\title{
Does current mental and physical health status differ by current physical activity level in Hispanic females ages 25- 44 in the general U.S. population?
}

\author{
Anna K Sanders, Laura J Washburn, Caroline F Clifton, Jaimie Story, Juliann G Castillo and Jessica L Hartos* \\ Department of Physician Assistant Studies, University of North Texas Health Science Center, Texas, USA
}

\begin{abstract}
Objectives: Research shows that mental and physical health are related to physical activity; however, few studies focus on Hispanic women. Therefore, the purpose of this study is to determine whether current mental and physical health differ by current physical activity level in Hispanic women ages 25 to 44 in the general population.

Methods: This cross-sectional analysis used 2017 BRFSS data for Hispanic women ages 25 to 44 from California (N=531), Colorado (N=222), Florida (N=495), New York $(\mathrm{N}=282)$, and Texas $(\mathrm{N}=498)$. Multiple logistic regression analysis for combined state data was used to assess the relationship separately for mental health and physical health with physical activity while controlling for state and health-related, demographic, and socioeconomic factors.

Results: About one-third of Hispanic women reported mental health issues (37\%), physical health issues (34\%), and physical inactivity (34\%) in the past 30 days. The results of adjusted analysis indicated that high physical activity was moderately related to physical health. In addition, activity limitations, health conditions, and healthcare access were moderately related to both mental and physical health; while weight status, alcohol use, and tobacco use were related only to mental health, with low to moderate effect sizes.

Conclusions: Overall, current physical activity was moderately related to current physical health, but not to current mental health in Hispanic women ages 25 to 44. However, multiple health-related factors were related to both physical and mental health issues in this target population. With the moderate prevalence of both mental and physical health issues in young adult Hispanic females, providers should always screen for these. Furthermore, because of moderate to high relations, providers should automatically screen for physical activity levels with physical health issues; for activity limitations and one or more health conditions with any physical or mental health issues; and for substance use with any mental health issues.
\end{abstract}

\section{Introduction}

General health encompasses both mental health and physical health and both are important for individual and societal functioning. For example, poor mental health is the leading cause of disability in the United States and creates an economic burden of three hundred billion dollars per year [1]. Up to $25 \%$ of U.S. adults suffer from a mental illness and over $50 \%$ of adults will develop at least one mental illness in their lifetime [1]. This is cause for concern because mental health impacts a person's emotional, social, and psychological wellbeing [2], with problems in mental health influencing behavior and interpersonal relationships [1,3]. In addition, poor physical health is related to the development of chronic health conditions [4-7]. In the U.S., seven out of ten leading causes of death are due to chronic diseases [8]. Such chronic diseases can include hypertension, diabetes, renal disease, cardiovascular risk factors [4,6], obesity, and cancer [7]. With the prevalence of some of these diseases on the rise, there is also an increase in costs for their associated treatments [7]. For example, the U.S. spends up to $\$ 147$ billion every year on health care costs related to obesity alone [8].

Several factors are known to play a role in a person's overall mental and physical health. Some of these factors include alcohol use and smoking $[2,4-7,9]$. In addition, economic hardship can contribute to a lower overall health status $[2,4,6]$, and lower education level is related to lower physical health [6]. Furthermore, health status can differ by lack of access to health care, which can result from financial, insurance, and language barriers $[6,10]$.

Moreover, research has shown a link between physical activity and positive mental and physical health $[10,11]$. Physical activity can be defined as movement of the body that results in changes in overall energy expenditure as related to fitness [12]. Physical activity has been shown to reduce depression and anxiety and lead to a positive selfconcept $[9,11,13]$. In addition, the physical benefits of exercise are well known, as a sedentary lifestyle can lead to health conditions such as hypertension, type 2 diabetes, and cardiovascular disease [3,12].

Despite the known benefits of being physically active, there are limited studies focusing on the relationship between physical activity and overall health in young-adult Hispanic women. Among the Hispanic population, it has been shown that there is a lack of interest in regular check-ups with primary care providers, which may result in

${ }^{\star}$ Correspondence to: Jessica L Hartos, Department of Physician Assistant Studies, University of North Texas Health Science Center, 3500 Camp Bowie Blvd, Fort Worth, Texas, 76107, USA, Tel: (817) 735-2454; Fax: (817) 735-2529; E-mail: jessica.hartos@unthsc.edu

Key words: mental health, physical health, physical activity, Hispanic, females Received: May 01, 2019; Accepted: May 23, 2019; Published: May 27, 2019 

population?

a higher prevalence of uncontrolled chronic conditions [6]. Over onethird of people in this population have a chronic health condition [10] and more than half of Hispanic women are overweight [6]. Additionally, less than $10 \%$ of Hispanic women may report regular physical activity [12], so research about the relationship between overall physical activity level and mental and physical health status is important to provide adequate advisement and treatment. Therefore, the purpose of this study is to assess whether current mental and physical health status differs by current physical activity level in Hispanic females ages 25-44 in the general population.

\section{Methods}

\section{Design}

This cross-sectional analysis used data from the 2017 Behavioral Risk Factor Surveillance System (BRFSS) conducted by the Centers for Disease Control and Prevention [14]. BRFSS is a nationwide annual survey system that collects prevalence data related to overall health, health risk behaviors, chronic health conditions, and preventative strategies among adults 18 and older in all 50 states, the District of Columbia, and three U.S. territories. Random digit dialing techniques for both landlines and cell phones are used to conduct more than 400,000 telephone interviews annually. The CDC then compiles all BRFSS data and gives researchers access to de-identified data for secondary data analyses. This study was given exempt status by the Institutional Review Board of the University of North Texas Health Science Center.

\section{Sample}

The samples for this study included Hispanic women ages 25 to 44 from California $(\mathrm{N}=531)$, Colorado $(\mathrm{N}=222)$, Florida $(\mathrm{N}=495)$, New York $(\mathrm{N}=282)$, and Texas $(\mathrm{N}=498)$ with data for physical health, mental health, and physical activity. We selected these states based on the higher prevalence of Hispanic women within our target population age range of 25-44 [15].

\section{Data}

The outcomes were mental health status and physical health status. Mental health status was originally measured by BRFSS asking participants, "Now thinking about your mental health, which includes stress, depression, and problems with emotions, for how many days during the past 30 days was your mental health not good?" Responses were measured quantitatively from 0-30 days. The answers to this question were then reversed to reflect "good" mental health, and because the responses were severely skewed (California $\mathrm{M}=26.09, \mathrm{SD}=7.70, \mathrm{R}$ =0-30; Colorado $\mathrm{M}=26.40, \mathrm{SD}=7.30, \mathrm{R}=0-30$; Florida $\mathrm{M}=26.41$, $\mathrm{SD}=7.66, \mathrm{R}=0-30$; New York $\mathrm{M}=26.14, \mathrm{SD}=7.89, \mathrm{R}=0-30$; Texas $\mathrm{M}=26.14, \mathrm{SD}=7.69, \mathrm{R}=0-30$ ), we dichotomized based on the mode, resulting in "30 days of good mental health" versus "less than 30 days".

Similarly, physical health status was originally measured by BRFSS asking participants "Now thinking about your physical health, which includes physical illness and injury, for how many days during the past 30 days was your physical health not good?" Responses were measured quantitatively from 0-30 days. The responses were then reversed to reflect days of "good" physical health in the past thirty days, and because the responses were severely skewed (California $\mathrm{M}=27.13, \mathrm{SD}=6.79, \mathrm{R}$ =0-30; Colorado $\mathrm{M}=26.98, \mathrm{SD}=7.29, \mathrm{R}=0-30$; Florida $\mathrm{M}=27.30$, $\mathrm{SD}=6.58, \mathrm{R}=0-30$; New York $\mathrm{M}=26.22, \mathrm{SD}=7.60, \mathrm{R}=0-30$; Texas $\mathrm{M}=$ $27, \mathrm{SD}=6.62, \mathrm{R}=0-30$ ), we dichotomized based on the mode, resulting in "30 days of good physical health" versus "less than 30 days".
The factor of interest, physical activity level, was measured in BRFSS by asking respondents a series of questions about types of activities and frequency of participation in the past month, and then categorizing responses as "inactive (less than 0 minutes), "insufficiently active" (11149 minutes), "active" (150-300 minutes), and "highly active" (>300 minutes).

The control variables included activity limitations, health conditions, weight status, healthcare access, alcohol use, tobacco use, age, marital status, education level, employment status, and income level. All variables and categories are shown in table 1. Activity limitations was measured by calculating the number of "yes" responses to having any of the following conditions: serious difficulty hearing, blind or serious difficulty seeing even with glasses, serious difficulty concentrating/remembering/making decisions, serious difficulty walking or climbing stairs, difficulty dressing or bathing, and difficulty doing errands alone, and then categorizing values as "zero" vs "one or more" activity limitations. Similarly, the number of health conditions was calculated as the number of "yes" responses to being diagnosed with any of the following conditions: coronary heart disease, stroke, skin cancer, cancer, chronic obstructive pulmonary disease, arthritis, depression, kidney disease, diabetes, and asthma, and then categorizing values as "zero", "one", or "two or more" health conditions. BRFSS calculated alcohol use as the average number of drink occasions per day and we categorized these as: "none" $(0)$, "light" $(<1)$, and "moderate or excessive" (1-4+ females, 1-5+ males) (CDC, 2018).

Analysis. Frequency distributions by state were used to describe the samples and determine any issues with the distribution of variables. We chose to combine data across all states for adjusted analysis because several variables had small numbers. Using the combined state data, multiple logistic regression analysis was conducted to determine the relationship between mental health status and physical activity, and physical health status and physical activity, after controlling for state and health-related, demographic, and socioeconomic factors. Any observations with missing data for any variables were excluded from adjusted analysis. All analyses were conducted in STATA version 15.1 (Copyright 1985-2017 StataCorp LLC).

\section{Results}

\section{Participant characteristics}

Of the Hispanic females ages 25-44, about one-third reported less than 30 days of good mental health $(\mathrm{n}=743,37 \%)$ and less than 30 days of good physical health $(n=688,34 \%)$ in the last 30 days. Table 1 lists other participant characteristics. As shown in table 1, about one-third of the participants reported physical inactivity in the past 30 days and less than one-third reported being highly active. For other health concerns, most reported no activity limitations, and the majority reported no health conditions and being either overweight or obese. For healthcare access, most reported that the cost of healthcare was not a barrier to healthcare. For health behaviors, the majority reported no alcohol use in the past 30 days and most reported never smoking. For demographic characteristics, about half reported being 25 to 34 years old and married. For socioeconomic status, most reported not graduating college or technical school; the majority reported being employed; and most reported an annual income level less than $\$ 50,000$.

\section{Results for mental health}

Table 1 also shows the results of multiple logistic regression analysis for Hispanic females ages 25 to 44, which indicated that after controlling 
Table 1. Participant characteristics and adjusted results for combined state data

\begin{tabular}{|c|c|c|c|c|c|c|c|c|}
\hline \multirow{3}{*}{ Model } & \multirow{2}{*}{\multicolumn{2}{|c|}{$\begin{array}{l}\text { Descriptive } \\
\text { Statistics }\end{array}$}} & \multicolumn{3}{|c|}{ Mental Health } & \multicolumn{3}{|c|}{ Physical Health } \\
\hline & & & \multirow{2}{*}{$A O R$} & \multicolumn{2}{|c|}{$95 \% \mathrm{CI}$} & \multirow{2}{*}{$A O R$} & \multicolumn{2}{|c|}{$95 \% \mathrm{CI}$} \\
\hline & $\mathbf{N}$ & $\%$ & & Low & High & & Low & High \\
\hline Physical Activity & 2028 & 100 & & & & & & \\
\hline Inactive & 684 & 34 & ref & - & - & ref & - & - \\
\hline Insufficiently active & 457 & 23 & 0.70 & 0.49 & 1.00 & 1.20 & 0.84 & 1.71 \\
\hline Active & 386 & 19 & 1.07 & 0.74 & 1.55 & 1.37 & 0.95 & 1.98 \\
\hline Highly active & 501 & 25 & 0.89 & 0.63 & 1.25 & 1.49 & 1.05 & 2.10 \\
\hline Activity Limitations & 2013 & 99 & & & & & & \\
\hline 0 & 1706 & 85 & ref & - & - & ref & - & - \\
\hline 1 or more & 307 & 15 & 0.36 & 0.24 & 0.52 & 0.38 & 0.26 & 0.55 \\
\hline Health Conditions & 1815 & 89 & & & & & & \\
\hline 0 & 934 & 51 & ref & - & - & ref & - & - \\
\hline 1 & 468 & 26 & 0.68 & 0.50 & 0.92 & 0.64 & 0.48 & 0.88 \\
\hline 2 or more & 413 & 23 & 0.50 & 0.36 & 0.69 & 0.36 & 0.26 & 0.50 \\
\hline Weight Status & 1672 & 82 & & & & & & \\
\hline Underweight or normal & 534 & 32 & ref & - & - & ref & - & - \\
\hline Overweight & 551 & 33 & 0.88 & 0.64 & 1.22 & 0.91 & 0.66 & 1.26 \\
\hline Obese & 587 & 35 & 0.70 & 0.50 & .96 & 0.98 & 0.70 & 1.37 \\
\hline Alcohol Use & 1938 & 96 & & & & & & \\
\hline None & 1143 & 59 & ref & - & - & ref & - & - \\
\hline Light & 423 & 22 & 0.80 & 0.60 & 1.13 & 0.84 & 0.61 & 1.16 \\
\hline Moderate or excessive & 372 & 19 & 0.51 & 0.36 & 0.72 & 0.94 & 0.66 & 1.34 \\
\hline Tobacco Use & 2022 & 100 & & & & & & \\
\hline Never smoker & 1630 & 81 & ref & - & - & ref & - & - \\
\hline Former smoker & 202 & 10 & 0.47 & 0.32 & 0.69 & 0.72 & 0.48 & 1.08 \\
\hline Current smoker & 190 & 9 & 0.56 & 0.37 & 0.86 & 0.69 & 0.45 & 1.07 \\
\hline Age & 2028 & 100 & & & & & & \\
\hline $25-34$ & 1017 & 50 & ref & - & - & ref & - & - \\
\hline $35-44$ & 1011 & 50 & 0.84 & 0.65 & 1.09 & 0.93 & 0.72 & 1.20 \\
\hline Marital Status & 2018 & 100 & & & & & & \\
\hline Not married & 986 & 49 & ref & - & - & ref & - & - \\
\hline Married & 1032 & 51 & 1.16 & 0.89 & 1.51 & 0.88 & 0.67 & 1.16 \\
\hline Education Level & 2023 & 100 & & & & & & \\
\hline Did not graduate & 1527 & 75 & ref & - & - & ref & - & - \\
\hline Graduated college & 496 & 25 & 0.70 & 0.51 & 0.96 & 0.72 & 0.52 & 0.99 \\
\hline Employment Status & 2007 & 99 & & & & & & \\
\hline Not employed & 906 & 45 & ref & - & - & ref & - & - \\
\hline Employed & 1101 & 55 & 0.90 & 0.68 & 1.19 & 0.94 & 0.71 & 1.25 \\
\hline Income Level & 1754 & 86 & & & & & & \\
\hline Less than $\$ 50,000$ & 1310 & 75 & ref & - & - & ref & - & - \\
\hline$\$ 50,000$ or more & 444 & 25 & 0.73 & 0.52 & 1.02 & 1.25 & 0.88 & 1.79 \\
\hline Healthcare Access & 2023 & 100 & & & & & & \\
\hline Cost did not preclude & 1487 & 74 & ref & - & - & ref & - & - \\
\hline $\begin{array}{l}\text { Cost precluded health } \\
\text { care }\end{array}$ & 536 & 27 & 0.65 & 0.49 & 0.88 & 0.56 & 0.41 & 0.75 \\
\hline State & 2028 & 100 & & & & & & \\
\hline California & 531 & 26 & ref & - & - & ref & - & - \\
\hline Colorado & 222 & 11 & 1.07 & 0.68 & 1.71 & 1.27 & 0.77 & 2.09 \\
\hline Florida & 495 & 24 & 1.31 & 0.91 & 1.90 & 1.14 & 0.79 & 1.66 \\
\hline New York & 282 & 14 & 1.18 & 0.78 & 1.77 & 0.60 & 0.41 & 0.90 \\
\hline Texas & 498 & 25 & 0.94 & 0.67 & 1.33 & 0.94 & 0.66 & 1.34 \\
\hline
\end{tabular}

$\mathrm{AOR}=$ adjusted odds ratio; $95 \%$ confidence intervals; ref=referent group; boldface indicates significance (AORs with $95 \% \mathrm{CI}$ that do not include 1.00 are significant).

for all other variables in the model, mental health was not significantly related to physical activity. However, compared to their referent groups, the following participants were less likely to report good mental health with various effect sizes: those who reported having one or more activity limitations (large effect size), having one health condition (moderate effect size), having two or more health conditions (moderate effect size), being obese (small effect size), having cost preclude access to healthcare (small effect size), reporting moderate or excessive alcohol use (moderate effect size), being a former smoker (moderate effect size), and being a current smoker (moderate effect size).

\section{Results for physical health}

Also shown in table 1 , the results of multiple logistic regression analysis for Hispanic females ages 25 to 44 indicated that after controlling for all other variables in the model, physical health was significantly related to physical activity. Participants were about 1.5 times more likely to report good physical health if they were highly active compared to those who were inactive. In contrast, compared to their referent groups, the following participants were less likely to report good physical health with moderate to large effect sizes: those who reported having one or more activity limitations (large effect size), having one health condition (moderate effect size), having two or more health conditions (large effect size), and having cost preclude access to healthcare (moderate effect size).

\section{Discussion}

The purpose of our study was to determine whether current mental and physical health status differ by current physical activity level in Hispanic females ages 25 to 44 in the general population. Descriptive statistics indicated that about one-third of participants reported mental health issues, physical health issues, and physical inactivity. Results of adjusted analysis indicated that physical activity was moderately related to physical health but not to mental health. Prior research showed significant relationships between mental health status and physical activity $[9,11,13]$ as well as physical health status and physical activity [4]. Differences may result from different target populations, as ours focused on young adult Hispanic women and prior studies included both men and women of all ages and did not specify results by race or gender.

Additionally, the results of our study indicated that both physical health and mental health in this target population were significantly related to having one or more activity limitations and health conditions. Previous research has also shown a relationship between lower mental and physical health and more activity limitations [16]. Also, existing studies have shown a relationship between poor mental health and chronic physical illnesses [2,5], as well as a relationship between poor physical health and higher risk of chronic diseases $[4,7,10]$. In addition, adjusted analysis showed that both mental and physical health were related to cost precluding healthcare access. Previous studies have also shown that a lack of healthcare access is related to physical health status $[6,10]$. Adjusted analysis also indicated that only mental health was significantly related to an obese weight status, moderate or excessive alcohol use, and being a former or current smoker. Previous studies have also shown that poor mental health is related to obesity [17], as well as alcohol and tobacco use [2,5,9]. However, other studies showed a relationship between alcohol and tobacco use and physical health as well $[4,6,7]$. Discrepancies in findings could be due to the method in which alcohol and tobacco use were measured among various studies, such as longitudinal studies with five-year follow-up periods [7] and review studies discussing a broad range of research [6].

\section{Limitations}

The BRFSS 2017 data allowed for the use of large samples of Hispanic women ages 25 to 44 across multiple states for analysis. We were also able to perform adjusted analysis controlling for many categories of variables, which had been a weakness in past studies $[11,18]$. Moreover, by using the BRFSS data set, we were able to obtain 

population?

current measures for mental health status, physical health status, and physical activity, thus improving the relevance and accuracy of data collected for analysis. However, information regarding the severity and management, including medication use, of any mental or physical health issues were not available. In addition, lack of access to information regarding other behavioral factors such as diet and recreational drug use that had previously been found to be significantly related to mental health $[2,5,9]$ were not available. Furthermore, information regarding physical activity was limited to specific activities for exercise in the BRFSS survey and did not include every day or work-related activity levels.

\section{Conclusions}

Because this was a population-based study, results may generalize to Hispanic females ages 25 to 44 in primary care settings. The results of this study indicate that providers need to be aware of multiple factors that may be related to mental and physical health in this target population.

Healthcare providers may expect about one-third of Hispanic young adult females to report mental health issues, physical health issues, and physical inactivity. Thus, providers should automatically screen for mental and physical health issues in this target population, assess treatment and management of any physical or mental health issues, and make referrals to specialists as needed. In addition, with a moderate relationship between physical health and physical activity, providers should automatically screen for inactive lifestyles with any physical health issues, educate patients on the importance of physical activity, and encourage activities that fit within the patients' lifestyles.

In addition, providers may expect a very low prevalence of activity limitations and a moderate prevalence of multiple health conditions in this target population, both with moderate to high relations with both mental and physical health. Thus, providers should screen for all of these if patients present with symptoms of any and treat issues concurrently. Providers should educate patients on the management of comorbid mental or physical health conditions, assess compatibility of treatments for comorbid conditions, and make referrals to specialists as needed.

Moreover, providers may expect about one-third of this target population to be overweight or obese with a small relation to mental health status. Thus, providers should screen for both issues if symptoms are present for either; educate patients on a healthy diet, causes of obesity, surgical, and prescription options; and make referrals to weight loss specialists as needed. Furthermore, providers may expect a low to moderate prevalence of alcohol and tobacco use in this target population with a moderate relation to poor mental health. Thus, providers should screen for alcohol and tobacco use, provide education on alcohol misuse and recommendations for smoking cessation, and provide resources for substance abuse and tobacco cessation as needed.

\section{Conflict of interest}

The authors declare that no author has any conflicts of interest related to the conduct or findings of this study.

\section{References}

1. Reeves WC, Strine TW, Pratt LA, Thompson W, Ahluwalia I, et al. (2011) Mental illness surveillance among adults in the United States. MMWR Suppl 60: 1-29. [Crossref]

2. Centers for Disease Control and Prevention (CDC) (2018) Learn about mental illness. Available from: https://www.cdc.gov/mentalhealth/learn/index.htm

3. Bize R, Johnson JA, Plotnikoff RC (2007) Physical activity level and health-related quality of life in the general adult population: A systematic review. Prev Med 45: 401415. [Crossref]

4. Brown DW, Balluz LS, Heath GW, Moriarty DG, Ford ES, et al. (2003) Associations between recommended levels of physical activity and health related quality of life findings from the 2001 Behavioural Risk Factor Surveillance System (BRFSS) survey. Prev Med 37: 520-528. [Crossref]

5. Jane-Llopis E, Matytsina I (2006) Mental health and alcohol, drugs and tobacco: A review of the comorbidity between mental disorders and the use of alcohol, tobacco and illicit drugs. Drug Alcohol Rev 25: 515-536. [Crossref]

6. Morales LS, Laura M, Kington RS, Valdez RO, Escarce JJ (2002) Socioeconomic, cultural, and behavioral factors affecting Hispanic health outcomes. J Health Care Poor Underserved 13: 477-503. [Crossref]

7. Reiner M, Niermann C, Jekauc D, Woll A (2013) Long-term health benefits of physica activity - A systematic review of longitudinal studies. BMC Public Health 13: 813. [Crossref]

8. Centers for Disease Control and Prevention (CDC) (2016) Nutrition, Physical Activity, and Obesity: At a Glance 2016. Available from: https://www.cdc.gov/chronicdisease/ resources/publications/aag/dnpao.html

9. Dale H, Brassington L, King K (2014) The impact of healthy lifestyle interventions on mental health and wellbeing: A systematic review. Ment Health Rev 19: 1-26. [Crossref]

10. Russell L (2010) Fact Sheet: Health Disparities by Race and Ethnicity. Center for American Progress. Available from: https://www.americanprogress.org/issues/ healthcare/news/2010/12/16/8762/fact-sheet-health-disparities-by-race-and-ethnicity

11. Paluska SA, Schwenk TL (2000) Physical activity and mental health: current concepts Sports Med 29: 167-180. [Crossref]

12. D'Alonzo KT, Saimbert MK (2013) Hispanic women and physical activity: an integrative review. Annu Rev Nurs Res 31: 209-234. [Crossref]

13. Mandolesi L, Polverino A, Montuori S, Foti F, Ferraioli G, et al. (2018) Effects of physical exercise on cognitive functioning and wellbeing: Biological and psychological benefits. Front Psychol 9: 509. [Crossref]

14. Centers for Disease Control and Prevention (CDC) (2018) Behavioural Risk Factor Surveillance System: About BRFSS. Available from: https://www.cdc.gov/brfss/

15. Centers for Disease Control \& Prevention (CDC) (2017) BRFSS Prevalence \& Trends Data. Available from: https://www.cdc.gov/brfss/brfssprevalence/index.html

16. Bültmann U, Franche RL, Hogg-Johnson S, Côté P, Lee H, et al. (2007) Health status, work limitations, and return-to-work trajectories in injured workers with musculoskeletal disorders. Qual Life Res 16: 1167-1178. [Crossref]

17. Daumit GL, Dalcin AT, Jerome GJ, Young DR, Charleston J, et al. (2011) A behavioural weight loss intervention for persons with serious mental illness in psychiatric rehabilitation centers. Int J Obes 35: 1114-1123. [Crossref]

18. Bravata DM, Smith-Spangler C, Sundaram V, Gienger AL, Lin N, et al. (2007) Using pedometers to increase physical activity and improve health: A systematic review. JAMA 298: 2296-2304. [Crossref]

Copyright: (C2019 Sanders AK. This is an open-access article distributed under the terms of the Creative Commons Attribution License, which permits unrestricted use, distribution, and reproduction in any medium, provided the original author and source are credited. 